\title{
Need supportive teaching in practice: a narrative analysis in schools with contrasting educational approaches
}

\author{
Kim Stroet • Marie-Christine Opdenakker • \\ Alexander Minnaert
}

Received: 1 October 2013 / Accepted: 7 January 2015 / Published: 12 June 2015

(C) The Author(s) 2015. This article is published with open access at Springerlink.com

\begin{abstract}
Research on self-determination theory (SDT) has shown that positive learning outcomes accrue in classrooms that support students' needs for autonomy, competence, and relatedness. Studies on what need supportive teaching entails in practice are, however, scarce. In the present study, we aimed to gain in-depth understanding of typical manifestations of the positive (autonomy support, structure, involvement) and negative (autonomy thwart, chaos, disaffection or reject) dimensions of need supportive teaching by relating these to educational approaches of schools. For this purpose, we conducted a narrative analysis of teacher-student interactions in two contrasting cases: A prototypical traditional class and a prototypical social constructivist class. In both classes, we analysed lessons in math and in mother language spread over the grade-7 year of secondary education. The results indicated striking differences between both classes in manifestations of need supportive teaching as well as similarities. The findings have implications for translating SDT to educational practice as they help make concrete the theoretical construct of need supportive teaching as well as further understanding of how SDT-interventions can be implemented in practice.
\end{abstract}

\footnotetext{
K. Stroet · A. Minnaert

Centre for Special Needs Education and Youth Care, University of Groningen, Grote Rozenstraat 38, 9712 TJ Groningen, The Netherlands

M.-C. Opdenakker

Groningen Institute for Educational Sciences (GION), University of Groningen, Grote Rozenstraat 3, 9712 TG Groningen, The Netherlands

K. Stroet $(\varangle)$

Department of Education and Child Studies, Leiden University, Wassenaarseweg 52, 2333 AK Leiden, The Netherlands

e-mail: k.f.a.stroet@fsw.leidenuniv.nl
} 
Keywords Self-determination theory - Social constructivism - Teacher-student interactions · Early adolescence $\cdot$ Lesson observation

\section{Introduction}

Motivation and engagement are critical for the active, self-constructed, and intentional process of learning. In Self-Determination Theory (SDT, Deci and Ryan 1985; Ryan and Deci 2000), it is assumed that curiosity about the environment and interest in both learning and skill development are inherent in human nature; the daily practices in a classroom can, however, either foster or undermine these volitional motivational processes. Whereas SDT research is clear in showing that positive learning outcomes accrue in classrooms that support students' needs for autonomy, competence, and relatedness (for reviews see Reeve 2002, 2009; Niemiec and Ryan 2009; Stroet et al. 2013), much less is known about the multiple ways in which need supportive teaching is manifested in practice. The present study is positioned within the increasing number of studies focused on gaining in-depth understanding of what is going on in classrooms (Stefanou et al. 2004; Perry et al. 2006) as we conducted a fine-grained comparison between typical manifestations of need supportive teaching in schools with contrasting educational approaches.

The types of schools that were the focus of this study either had a more traditional, teacher-centred approach to education or a social constructivist approach that was highly innovative and student-centred. In traditional views, the emphasis is laid on reproduction of knowledge that is transmitted in the learning process and teachers are expected to take a large degree of responsibility in structuring their students' learning processes (Shuell 1996). In contrast, in social constructivist views learning is considered not so much a reproductive but instead an active and constructive process, responsibility for which should gradually be transferred to the students themselves (Marshall 1988; Shuell 1996). Both approaches to education are influential in Western countries, as over the past decades many schools have incorporated elements of innovative, student-centred instruction, often to combine these with elements of traditional instruction.

What need supportive teaching entails in practice relates to educational approaches of schools. Theoretical notions on instruction are partially shared between SDT and social constructivism, e.g. both emphasise students' autonomy or volition in their learning. Consequently, social constructivist schools would be expected to (intentionally) trigger specific manifestations of autonomy support. Because implementing an educational approach in practice tends to have much broader consequences than accounted for in theory (Slavin 2012), next to such direct and "intended" triggers, in both types of schools, indirect and "unintended" triggers will be apparent. In the present study, we incorporated effects of both as we related typical manifestations of need supportive teaching to educational approaches as implemented in practice. For this aim, we compared types of schools in the context of Dutch education, which is particularly suitable as Dutch schools differ in the educational approaches that ground their practice.

In the next section, we continue by means of theoretical elaborations on SDT and need supportive teaching (Sect. 2.1). Then, we elaborate on traditional and social con- 
structivist views on learning and instruction, provide criteria for classifying schools working in accord with these respective educational approaches (Sect. 2.2), and discuss potential triggers of manifestations of need supportive teaching apparent in these educational approaches (Sect. 2.3). Finally, the present investigation is discussed (Sect. 2.4).

\section{Theoretical background}

\subsection{Self-determination theory}

SDT is a macro theory of human motivation that is built on two core assumptions. First, it is assumed that people possess an active tendency towards psychological growth. As a consequence of this tendency, people have innate strivings to exercise and elaborate their interests and to seek challenges, thereby stretching their capacities and expressing their talents. Second, it is assumed that people possess an active tendency towards integration, with the integration of that what is experienced providing the basis for a coherent sense of self. As a consequence of this latter tendency, people have innate strivings both to be causal agents (autonomous aspect) and to integrate themselves with others, thereby internalising the knowledge, customs, and values that surround them (homonymous aspect). When people are able to act in accord with these two natural tendencies, they will be motivated to learn and develop their skills by exercising and elaborating their personal interests or by pursuing those goals they personally value. Such motivation is regulated autonomously, and contrasts motivation that is regulated by control, i.e. by feelings of pressure by others or obligation to perform the task at hand (Deci and Ryan 1985; Ryan and Connell 1989). Autonomous motivation has been shown to provoke high quality learning (e.g. Gottfried 1985; Grolnick et al. 1991).

Based on the two core assumptions of SDT described above, three fundamental human needs can be distinguished, satisfaction of which fosters the volitional processes involved in high quality learning. First, the need for autonomy stems from the inherent desire people have to be causal agents and to experience volition. This need is closely associated with the autonomous aspect of the tendency towards integration. Second, the need for competence is closely related to people's active tendency toward psychological growth, as it refers to the need to feel effective, while at the same time exercising and expressing one's capacities. Third, the need for relatedness concerns the desire to form and maintain strong and stable interpersonal relationships, to connect with and be accepted by others, and to belong (Baumeister and Leary 1995; Bowlby 1979; Harlow 1958; Ryan 1995). The need for relatedness is associated with the homonymous aspect of the tendency toward integration that incorporates people's tendency to internalise the knowledge, customs, and values that surround them, particularly when encouraged to do so by related others.

A need supportive teaching style might imply beliefs about the nature of student motivation, but it is not a prescribed set of techniques and strategies (Reeve 2006). Consequentially, a differential approach is required in studying teacher-student interactions that takes into consideration the context in which teaching takes place (e.g. Malinowski 1930). A potential difficulty in the interpretation of teacher-student inter- 
actions is that they take place within the context of a classroom, with a large number of students being present. A classroom is a public place where behaviour is witnessed by a group of people, and in which a lot of things happen at the same time, competing for the attention of both the students and the teacher (Doyle 1986). Hence, teacherstudent interactions affect not only the student(s) involved in the interaction itself, but also those who are not directly involved.

Despite these potential difficulties in interpreting teacher-student interactions, educational literature generally agrees upon three dimensions of need supportive teaching that complement each other in their effects on students' need satisfaction (Connell and Wellborn 1991). The first positive dimension of need supportive teaching is autonomy support which opposes the first negative dimension of autonomy thwart. Teaching is autonomy supportive when it provides students with opportunities to express their own feelings, thoughts, and perspectives on the tasks at hand, whether positive or negative. Further, teachers can provide autonomy support by offering their student(s) choices, or, when choice is constrained, by fostering relevance by meaningfully connecting the learning activity to a goal that is of personal value to the student(s). More recent literature distinguishes between cognitive and non-cognitive autonomy support. For example, Stefanou et al. (2004) have argued in this regard that supporting students' autonomy by giving them choices on tasks, task material, or issues of organisation will foster their autonomy concerning form, media, or presentation, but not so much the cognitive process of learning. For this latter aim, 'cognitive choices' on content are required, i.e. setting problems for students that do not have clear-cut solutions and asking for explanations (Kunter and Baumert 2007) so that students can choose their own way of approaching a problem and define their own solution paths. It is this latter type of autonomy support that these authors argued would support students' independent thinking, and trigger their intrinsic desire to learn.

The second positive dimension is provision of structure which opposes the negative dimension of provision of chaos. Teachers can provide structure by communicating clear and consistent guidelines and by being available when students have questions. Further, provision of structure entails the fostering of students' views that success in the tasks learned in class depends mostly on internal controllable factors rather than inborn talent, and the provision of constructive, non-comparative feedback. Finally, an important component of structure is provision of guidance through giving step-by-step directions, thereby adjusting to the student(s).

The third positive dimension is involvement which opposes the dimension of disaffection or rejection. Teachers can express their involvement by demonstrating their affection and interest, by encouraging empathy and pro-social behaviour in the class, and by being available to all students in class. Further, teacher involvement consists in showing commitment to students' learning.

\subsection{Traditional and social constructivist instruction}

In the educational literature, distinct traditions have derived from different views on learning and instruction. Traditional and social constructivist educational approaches represent such distinct traditions that they can be contrasted on many of their perspectives on learning and instruction. 


\subsubsection{Traditional and social constructivist views on learning and instruction}

In traditional views on instruction, teachers are conceived as authorities who should take a large responsibility for the various steps in students' learning processes. The teachers are expected to disseminate knowledge through lectures and verbal exchanges (Shuell 1996), and structure the course material itself, as well as the way in which it is provided (Gibbs 1992; Boekaerts and Niemivirta 2000; Bolhuis and Voeten 2001). Students are expected to focus on the receipt of knowledge (Greeno et al. 1996; Prince 2004), and practice assigned exercises individually or in small groups. Ideally, they should be guided through a series of exercises systematically (Doyle 1983), until they have reached the learning goals as set by the teacher. In order to avoid distraction by irrelevant stimuli, tasks should largely be decontextualized (Greeno et al. 1996). Finally, the function of assessment is considered to be in monitoring how much students have learned and providing them with prompt feedback on the quality of their performance (Greeno et al. 1996).

After the cognitive revolution of the 1970s, prominent views on learning and instruction changed. These changed views have been incorporated in the social constructivist approaches toward education that emerged in convergence with theorists such as Vygotsky (1962, 1978), as well as the modern cognitive science perspective (see Shuell 1996; Hickey 1997). In these social constructivist views, the teachers are expected to provide students with guidance (Shuell 1996), while, at the same time, leaving them with a large responsibility for the cognitive and metacognitive aspects of their own learning processes such as their choice of learning goals (Gibbs 1992). Ideally, a gradual transfer of learning functions from teachers to students is realized (Shuell 1996; Vermunt and Verloop 1999; Boekaerts 2002). Further, learning is considered to be governed not only by cognitive, but also by situational and social factors. The former of these two notions entails the importance of providing students with contextualised tasks in an authentic context (Shuell 1996); as individual differences exist in what defines authentic contexts, students should be involved in choosing their own learning activities. The latter of these two notions stems from the idea that knowledge is constructed within dialogue (Toulmin 1972), and has resulted in the social constructivist view that both dialogue among students and between students and teachers should be stimulated (Shuell 1996). Finally, in social constructivist views, the function of assessment is in providing both the teacher and the student with information on the student's learning process, and, therefore, should primarily be formative instead of summative (Shepard 2000; Adams 2006).

\subsubsection{Traditional and social constructivist schools}

When we refer to 'prototypically traditional' or 'prototypically social constructivist' schools, we mean schools that adhere strongly to the respective educational approach. Criteria for classifying schools as 'prototypically traditional' are that (1) all lessons are taught in the same groups of students, (2) these lessons mostly consist of the teacher explaining subject matter frontally and students working on assignments that the teacher provides to the class as a whole, and (3) more summative instead of formative evaluation methods are used. 
For the purpose of selecting 'prototypical social constructivist schools', we used the criteria formulated for the Dutch context by Oostdam et al. (2006) based on the wide array of literature on social constructivist instruction. According to these criteria, social constructivist schools can be distinguished from traditional schools as: (1) more attention is paid to higher-order skills of self-regulation and metacognition, (2) students share responsibility for their own learning process and the learning goals they choose, (3) more formative instead of summative evaluation methods are used to evaluate students' work, (4) learning takes place within an authentic context, and (5) learning is considered to be a social activity.

\subsection{Possible triggers entailed in traditional and social constructivist views on instruction}

In the Introduction, we argued that manifestations of need supportive teaching are shaped by the triggers entailed in schools' educational approaches. Thus far, little is known on how need supportive teaching is shaped by contextual triggers. An exception is the work of Reeve (2009), who, mainly referring to experimental SDT literature, provided an overview of what he labelled "pressures from above" (Pelletier et al. 2002) that trigger teachers to adopt an autonomy thwarting motivational style. We continue by elaborating on two pressures that seem of relevance to the present study.

The first "pressure from above" consists in teachers feeling they have to ensure that their students perform up to a certain standard (based on Deci et al. 1982), triggering them to adopt a controlling motivational style that includes using directives and criticisms and providing little opportunities for student input. Although this pressure probably is valid for teachers in all types of schools, the effect of this "pressure from above" might be reinforced by a traditional educational approach in which the teachers explicitly are expected to take a large responsibility for the various steps in students' learning processes.

The second pressure consists in the inherent power differences that define teacherstudent relationships. Again, we expect this pressure to be more apparent in a traditional than in a social constructivist educational approach, as in traditional views teachers are authorities, whereas in social constructivist views learning is a social process and dialogue between teachers and students should be stimulated.

\subsection{Present investigation}

In the present study, we aimed to gain an understanding of what need supportive teaching entails in practice by relating manifestations of need supportive teaching to educational approaches of schools. With this intention, we conducted a narrative analysis of videotaped teacher-student interactions in two classes highly prototypical for their respective educational approach. In both classes, we analysed lessons in math and in mother language, as these are considered key subjects in the curriculum. 


\section{Methods}

\subsection{Participants}

\subsubsection{Participating schools}

The collection of video material in the two cases that were the focus of the present study was part of a larger data collection that took place in the school year 2010-2011. In this larger data collection, a total of twenty grade-7 classes (age 12-13) and their teachers in math and mother language (Dutch) participated. All of these classes were at the prevocational level of secondary education ('vmbo'), which is the lowest of the three mainstream tracks in the Dutch educational system, and is attended by more than half of the students (Dutch Inspectorate of Education 2012). The participating classes were divided into prototypical traditional and prototypical social constructivist schools as well as schools that combined elements of both.

For the selection of these schools, we used the criteria for prototypical traditional and prototypical social constructivist schools as described in the Theoretical Background. For the aim of collected information we coded information provided on websites of 141 schools and we collected information on daily practices in these schools collected for a study by Oostdam et al. (2006) and provided by the Dutch Inspectorate of Education (for a more detailed report of school selection, the interested reader is referred to Stroet 2014). Schools were classified as prototypically traditional when they met all of the criteria for prototypically traditional schools, none of those for prototypically social constructivist schools, and had worked in accord with a traditional approach for at least four years. Schools were classified as prototypically social constructivist when they met all of the criteria for prototypically social constructivist schools, none of those for prototypically traditional schools, and had worked in accord with a social constructivist approach for at least four years. Schools were classified as combined when they combined elements of both educational approaches. Heads of departments of selected schools were contacted and asked to participate in the study; they decided on their willingness to do so after consulting their teams only.

\subsubsection{Case studies}

We selected two classes as contrasting and critical cases for the present study: one drawn from the group of prototypical traditional schools and one drawn from the group of prototypical social constructivist schools. We categorised the schools from which we drew these two classes as representing strong contrasts because they scored even more positive on the criteria for their respective types than the other schools did. For example, in the selected traditional school, lessons did not only mostly, but almost completely consist in the teacher explaining subject matter frontally and students working on assignments that the teacher provided to the class as a whole (criterion 2). We based this categorisation on information gathered during the selection process as well as in lesson observations and discussions with teachers and head of departments. Further, in conversations with the heads of departments, we established both classes that were selected as cases, as well as their teachers, to be representative for their 
school. The two teachers in math and two teachers in mother language (one of each per class) that participated in the present study had worked in the respective schools for at least 3 years.

The prototypical traditional class (class T) was located in a middle-class, urban area in the Western part of the Netherlands and consisted of 24 students: 11 girls and 13 boys. The vast majority of students were of Dutch origin. Both participating teachers in this class were aged between 35 and 45; the math teacher was a male, the teacher in mother language a female. All lessons in class T had a scheduled duration of $45 \mathrm{~min}$, with students having six lessons a day on average. Weekly, four lessons in math and four lessons in mother language were scheduled. All lessons were taught in the same group of students and consisted of a frontal part and a part in which the students simultaneously worked on assignments provided to the class as a whole. For math, one of two prominent textbooks was used ("Moderne Wiskunde" 1 " and not "Getal en Ruimte ${ }^{1 "}$; a large majority of schools in the Netherlands uses either of these two textbooks ${ }^{2}$ ). For mother language, a textbook was used in combination with learning material designed by the teachers themselves.

The prototypical social constructivist class (class SC) was located in an upperclass, urban area in the Western part of the Netherlands and consisted of 27 students: 16 girls and 11 boys. The vast majority of students were of Dutch origin. The math teacher in this class was a male, aged between 25 and 35, and the teacher in mother language was a female aged between 35 and 45 . As in class $\mathrm{T}$, all lessons in class SC had a scheduled duration of $45 \mathrm{~min}$, with students having six lessons a day on average. For math, the same textbook was used as in class T, and for mother language, as in class $\mathrm{T}$, a textbook was used combined with learning material designed by the teachers themselves. In contrast to class T, in class SC different types of lessons were scheduled, and students were provided with period-assignments for which they had several weeks to finish. For both math and mother language, every week the teachers used one frontal lesson to explain the subject matter and new period-assignments, while the other three lessons students could use to work on their period-assignments.

\subsection{Procedure of data collection}

Before the start of the study, consent letters had been sent to the parent(s)/guardian(s) of the students, none of whom declined the participation of their child. At the beginning of the school year, the participating teachers received information packages that included global information on the purpose of the study, information on the data collection, and a signed document assuring the anonymous processing of all video material. Throughout the data collection it was clear for both students and teachers that the interest was in classroom communication as usual and it was emphasised that the video material would be accessible to involved researchers only.

\footnotetext{
1 Groningen, the Netherlands: Noordhoff Publishers.

2 "Getal en Ruimte" (60\%) and "Moderne Wiskunde" (30\%); Noordhoff publishers, personal communication, January 2, 2014.
} 
Four times during the course of the school year, in each class two lessons in math and two lessons in mother language were videotaped, yielding a total of 16 videotaped lessons per class. The videos were shot by four cameramen in total (three trained university students and the first author), one or two of whom were present at a time. Classrooms were equipped with two cameras: one 'fixed' camera, facing the class, and one 'action' camera, operated by a cameraman at the back of the class and directed to the teacher (during frontal instruction) or to on-going teacher-student interactions (when students were working individually or in small groups). In order for all teacher-student interactions, including those that were softly spoken, to be audible on the videotapes, the teachers were asked to carry a small wireless microphone. The cameramen always tried to limit interference to an absolute minimum, so the teacher and the class could proceed with their lesson as usual.

\subsection{Analytical approach}

To relate manifestations of need supportive teaching to educational approaches of schools, we carried out a fine-grained narrative analysis of videotaped teacherstudent interactions in two classes highly prototypical for their respective educational approach. To gain insight into how educational approaches of schools triggered typical manifestations of need supportive teaching, we relied on qualitative process analysis. This type of analysis is based on the idea that the existence of causal relations can be established not only by repeatedly associating events, but that it would also suffice to observe one case in which cause, effect, as well as causal relation are present (see Maxwell 2004; Flyvbjerg 2006). In our analysis, we pursued gaining insight into causal processes by closely observing and discussing the video material as well as by relating it to the theoretical views that grounded the respective educational approaches.

In this research, the prototypical traditional and the prototypical social constructivist classes are considered as representing not only contrasting but also critical cases (e.g. Flyvbjerg 2006). A critical case permits logical deduction of the type: "If this is (not) valid for this case, then it applies to all (no) cases." (Flyvbjerg 2006, p. 230). In our reasoning, if manifestations of need supportive teaching are not linked with an educational approach in a class highly prototypical for this approach, they are not linked with this educational approach in other classes either.

The analyses were limited to teacher-student interactions, and communication among students that did not involve the teacher was not taken into consideration. Further, the analyses were focused, first and foremost, on comparing need supportive teaching between class $\mathrm{T}$ and class $\mathrm{SC}$, and not on differences between individual teachers or on development of need supportive teaching over time. Whenever we found clear differences between teachers or over time, these are, however, discussed. In the Results section, the research question is answered by a discussion of narratives originating from both classrooms. In our interpretation of these narratives, we used a differential approach and followed the notion that a statement cannot be detached from the situation in which it has been uttered (e.g. Malinowski 1930). 


\subsection{Procedure of analysis}

In preparation for the narrative analysis, the first author coded all video material using a rating sheet that assessed need supportive teaching (Stroet 2014) and a rating sheet that assessed lesson phases (based on Klette et al. 2005; for descriptions see below). These codings provided us with a clustering of video-fragments useful for detecting patterns in manifestations of need supportive teaching in both classes. In addition, the codings provided quantitative information on levels of need supportive teaching in both classes that we used as background information.

To analyse the video-taped narratives, the first author initiated discussion sessions both among the authors and with university students, thereby following recommendations on data sessions by Heath et al. (2010). These recommendations include taking time to scrutinise selected video fragments to try and work out what is happening instead of quickly moving over to other examples.

Lesson phases The rating sheet we used to assess lesson phases is based on the work of Klette et al. (2005) and is presented in the first part of Table 1. The rating sheet distinguished between teacher-individual/small group interactions and class instruction, as these two phases of lessons have very different dynamics. Further, lessons were distinguished in phases of task management, content, and process. Phases of task management consisted of the teachers providing instructions regarding assignments, including homework, material resources, and grouping, as well as in ordering procedures, including comments on misbehaviour. Phases of content consisted in instruction or discussion on subject matter. In phases of process students' learning processes were discussed. Finally, phases were not included in the analysis when they consisted of other business, such as the class getting prepared to start the lesson or messages regarding school trips. Consequently, these phases were coded as 'other'.

Need supportive teaching The rating sheet we used to assess need supportive teaching was used and validated previously in schools for secondary education by Stroet (2014). All coding was conducted by the first author. To establish interrater reliability with another researcher working on SDT, two lessons were double coded and Cohen's kappa coefficient was calculated. This yielded values of .70 for the dimension of autonomy support/autonomy thwart, .71 for structure/chaos, and .75 for involvement/disaffection. Teacher-student interactions were classified as either not being relevant in terms of need supportive teaching or as providing students with one or more of the positive dimensions (autonomy support, structure, and/or involvement) or negative dimensions (autonomy thwart, chaos, and/or disaffection or reject) of need supportive teaching. If a teacher-student interaction could not be coded (e.g. because it was inaudible), then a "no code" was used; in practice this did not occur. All our codes were linked to the complete video fragments they related to, so we could adequately map both frequency of occurrence and duration.

Tables The quantitative background information that was generated by our coding is presented in Tables 2 and 3. In Table 2, duration and frequency are presented for the positive and negative dimensions of need supportive teaching, split up for class $\mathrm{T}$ 
Table 1 Rating sheets

\section{Lesson phases ${ }^{\mathrm{a}}$}

Teachers interact with whom:

Class/individual or small groups of students

Within class instruction:

Content related instruction/process related instruction/(task) management/other

Within class instruction, content related:

Monologue/dialogue

Within interaction with individual or small groups of students:

Content related instruction/process related instruction/(task) management/other

Teachers' autonomy support/thwart ${ }^{\mathrm{b}}$

Choice

Creating opportunities for students to work in their own way and incorporating their interests, curiosity, or sense of challenge into the lesson.

\section{Fostering relevance}

Meaningfully connecting the learning activity to a goal that is of personal value to the student(s).

\section{Respect}

Listening and responding to students' feelings, thoughts, perspectives, and complaints.

\section{Teachers' provision of structure/chaos}

\section{Clarity}

Clear organisation that includes communicating clear and consistent guidelines and being available when students have questions on task management (coded per phase).

\section{Guidance}

Being available to answer questions on content (coded per phase) and providing step-by-step directions when needed, thereby adjusting to the student(s).

\section{Encouragement}

Fostering non-competitive learning structures, fostering views that success in learning activities depends on internal controllable factors rather than inborn talent, and demanding effort.

\section{Control}

Keeping possession of the learning material, providing solutions before students have time to reflect by themselves, exerting pressure, or disrupting students' natural rhythm by not allowing them to realise their action plans.

\section{Forcing meaningless activities}

Actively attempting to compel students to do things they find boring or meaningless or connecting the learning activity to an extrinsic goal.

\section{Disrespect}

Not allowing differences in opinion, complaints, or negative affect.

\section{No clarity}

No clear organisation or not being available when students have questions on task management (coded per phase).

\section{No guidance}

Not being available to answer questions on content (coded per phase) and clearly not monitoring or adjusting to students' level of comprehension.

\section{Discouragement}

Fostering competitive learning structures, fostering students' views that success in learning activities depends mostly on inborn talent, not demanding effort, or treating poor performance evaluative. 
Table 1 continued

\section{Informational feedback}

Providing constructive, non-comparative feedback focused on helping students gain control over valued outcomes.

\section{Teachers' involvement/disaffection or rejection}

\section{Affection}

Showing warmth, demonstrating interest, fostering a sense of connectedness by encouraging empathy and pro-social behaviour, and treating students fair and consequent.

\section{Attunement}

Showing understanding of the students on what is of importance for them.

\section{Dedication of resources}

Being available to all students in class.

\section{Dependability}

Being available to offer support and showing commitment to students' learning.

\section{Evaluative feedback}

Providing comparative, feedback focused on evaluating students' performance, or feedback with a controlling locution, e.g.: "Good, you did just as you should".

\section{Disaffection}

Talking in an unfriendly tone, showing lack of interest, communicating that students do not belong, or treating students unfair and inconsequent.

\section{No attunement}

Showing no understanding of the students on what is of importance for them.

\section{No dedication of resources}

Not being available to (all) students, e.g. appearing occupied with other things or walking out of the classroom.

\section{No dependability}

Clearly not being available to offer support and showing no commitment to students' learning.

\footnotetext{
a Transitions coded

${ }^{\mathrm{b}}$ Coded per teacher-student interaction, unless indicated otherwise
}

Table 2 Levels (duration and frequency) of need support and need thwart in class T and class SC

\begin{tabular}{|c|c|c|c|c|c|c|c|c|}
\hline & \multicolumn{4}{|c|}{ Class T } & \multicolumn{4}{|c|}{ Class SC } \\
\hline & \multicolumn{2}{|l|}{ Class } & \multicolumn{2}{|c|}{ Individual/small group } & \multicolumn{2}{|l|}{ Class } & \multicolumn{2}{|c|}{ Individual/small group } \\
\hline & Dur. $^{\mathrm{a}}$ & Freq. $^{\mathrm{b}}$ & Dur. $^{\mathrm{a}}$ & Freq. ${ }^{\mathrm{b}}$ & Dur. $^{\mathrm{a}}$ & Freq. ${ }^{b}$ & Dur. $^{\mathrm{a}}$ & Freq. ${ }^{b}$ \\
\hline Autonomy support & 8.9 & 17.8 & 4.6 & 5.1 & 26.9 & 29.4 & 28.8 & 15.9 \\
\hline Autonomy thwart & 3.7 & 7.5 & 26.6 & 19.4 & 0.8 & 0.4 & 2.0 & 1.7 \\
\hline Structure & 10.4 & 15.5 & 16.6 & 13.9 & 10.8 & 10.8 & 36.7 & 17.8 \\
\hline Chaos & 6.7 & 10.5 & 3.3 & 4.6 & 4.5 & 3.5 & 1.7 & 1.5 \\
\hline Involvement & 4.1 & 11.1 & 7.7 & 11.0 & 8.1 & 6.5 & 20.0 & 10.9 \\
\hline Disaffection or rejection & 1.1 & 2.2 & 10.5 & 13.9 & 1.4 & 0.4 & 2.2 & 1.3 \\
\hline
\end{tabular}

${ }^{a}$ Relative duration expressed as percentages of total phases

${ }^{\mathrm{b}}$ Relative frequency expressed as number of times per hour

and class SC and for class and individual/small group instruction. In both tables, the results of the coding have been aggregated over teachers (two per class) as well as measurement occasions (four per class). 
Table 3 Relative duration lesson phases ('task management', 'content', and 'process') and division of levels (duration) of autonomy support and autonomy thwart over these lesson phases in class $\mathrm{T}$ and class $\mathrm{SC}$

\begin{tabular}{|c|c|c|c|c|c|c|}
\hline \multirow[t]{4}{*}{ Duration $^{\mathrm{a}}$} & \multicolumn{3}{|l|}{ Class T } & \multicolumn{3}{|l|}{ Class SC } \\
\hline & Class & & Individual/small group & Class & & Individual/small group \\
\hline & 60.3 & & 28.5 & 27.5 & & 64.0 \\
\hline & Task Cont. & Proc. & Task Cont. Proc. & Task Cont. & Proc. & Task Cont. Proc. \\
\hline Duration $^{\mathrm{a}}$ & 13.546 .6 & 0.2 & 13.013 .7 & 12.315 .1 & 0.1 & $31.421 .9 \quad 10.7$ \\
\hline Autonomy support ${ }^{\mathrm{b}}$ & 0.911 .2 & 0.0 & $\begin{array}{lll}3.8 & 1.9 & 30.6\end{array}$ & 22.730 .6 & 0.0 & $23.1 \quad 11.5 \quad 78.6$ \\
\hline Autonomy thwart ${ }^{b}$ & $2.7 \quad 3.8$ & 38.4 & $10.8 \quad 41.0 \quad 27.2$ & $\begin{array}{ll}1.8 & 0.0\end{array}$ & 0.0 & $\begin{array}{lll}1.6 & 1.5 & 4.4\end{array}$ \\
\hline
\end{tabular}

\footnotetext{
${ }^{\text {a }}$ Relative duration expressed as percentages of total lessons. Per class, percentages do not completely add up to 100 as the phase 'other' was not included in the analyses

${ }^{\mathrm{b}}$ Relative duration expressed as percentages of total phases

'Task' refers to task management, 'Cont.' refers to content, 'Proc.' refers to process
}

Duration refers to the percentage of time spent on teacher-student interactions relevant in terms of a specific dimension of need supportive teaching. For example, a (fictitious) duration of ' 10 ' for 'class T', 'class instruction', 'autonomy support', would mean that $10 \%$ of class instruction in class $\mathrm{T}$ is spent on autonomy supportive interactions. Frequency refers to the number of times per hour that teacher-student interactions take place that are relevant in terms of a specific dimension of need supportive teaching. For example, a (fictitious) frequency of '10' for 'class T', 'class instruction', 'involvement', would mean that within class instruction in class $\mathrm{T}$ teachers expressed their involvement in, on average, 10 interactions per hour. In Table 3, the relative durations of the respective lesson phases are presented. Moreover, for autonomy support and autonomy thwart, durations of autonomy support and autonomy thwart are further divided over all the respective lesson phases. In the text we regularly refer to the levels of (dimensions of) need supportive teaching being high, low, or apparent occasionally. High refers to more than $17 \%$, low refers to $<7 \%$, and occasionally refers to everything in between. We have set these cut-off numbers based on insights acquired from watching the videos; we considered lessons high on a dimension to differ meaningfully from lessons low on the same dimension when we used these cut-off scores.

For the positive dimensions of autonomy support and structure and the negative dimensions of autonomy thwart and chaos we considered durations of teacher-student interactions to most properly indicate expressions of need support/thwart. For example, as longer provision of step-by-step directions seemed indicative of higher levels of structure or as the more time teachers took to provide autonomy support, the higher levels of autonomy support appeared. For the positive dimension of involvement and the negative dimension of disaffection, however, we considered frequency the most appropriate indication of its expression for two reasons. First, because, more than was the case for other dimensions, utterances seemed to provide involvement or disaffection rather independent of their duration. Second, because we found expressions 
of involvement and disaffection often to be manifested in a part of teacher-student interactions only, so that a focus on durations would somewhat mask the data.

In Sect. 4, we start with a brief overview of the quantitative background information on duration of lesson phases and levels of need supportive teaching as generated by our coding (Sect. 4.1). Then, we continue with our narrative analysis of manifestations of need supportive teaching in both classes (Sect. 4.2). First, we discuss the findings separately for class A and for class B and for class instruction and individual/small group discussion, then we discuss manifestations of need supportive teaching that appeared typical in both classes.

\section{Results}

4.1 Quantitative background information for class T and class SC

\subsubsection{Lesson phase durations}

The results as presented in Table 3 revealed three striking differences in terms of lesson phase durations between both classes. First, larger proportions of lessons were attributed to instruction to the class as a whole in class T $(60.3 \%)$ than in class SC $(27.5 \%)$. Second, larger proportions of interactions were attributed to content in class $\mathrm{T}(46.6 \%+13.7 \%)$ than in class SC $(15.1 \%+21.9 \%)$. Third, whereas in both classes approximately half of individual/small group instruction was attributed to task management $(13.5 \div 28.5$ vs. $31.4 \div 64.0 \%)$, the other halves of these phases were divided between content and process in class SC (21.9 and $10.7 \%)$ but attributed almost solely to content in class $\mathrm{T}(13.7$ and $1.8 \%)$.

\subsubsection{Need supportive teaching}

The results as presented in Table 2 revealed striking differences between both classes for durations of autonomy support both in phases of class and individual/small group instruction ( $8.9 \% / 4.6 \%$ in class T vs. $26.9 \% / 28.8 \%$ in class SC). Moreover, in phases of individual/small group instruction striking differences between classes were found for durations of autonomy thwart (26.6\% in class T vs. $0.8 \%$ in class SC), durations of structure ( $16.6 \%$ in class T vs. $36.7 \%$ in class SC) and frequency of disaffection (13.9 in class T vs. 1.3 in class SC). From Table 3 it can be seen that for class instruction the differences in durations of autonomy support stemmed from differences both in instruction on task management $(0.9 \%$ in class T vs. $22.7 \%$ in class SC), and on content $(11.2 \%$ in class T vs. $30.6 \%$ in class SC). The differences between both classes in levels of autonomy support and thwart in phases of individual/small group instruction appeared apparent both in instruction on task management $(3.8 \% / 10.8 \%$ in class $\mathrm{T}$ vs. $23.1 \% / 1.6 \%$ in class SC) and instruction on content $(1.9 \% / 41.0 \%$ in class T vs. $11.5 \% / 1.5 \%$ in class SC) as well.

The results as presented in Table 2 also revealed similarities in levels of need supportive teaching between both classes. In phases of class instruction it was relatively uncommon for the teachers to provide their students with autonomy thwart, chaos 
or disaffection, both in class T (3.7\%/6.7\%/2.2) and in class SC (0.8\%/4.5\%/0.4). Moreover, the teachers did occasionally provide their students with structure as well as involvement both in class T (10.4\%/11.1) and in class SC (10.8\%/6.5). In phases of individual/small group instruction, it was uncommon for the teachers to provide the students with chaos and they regularly expressed their involvement, both in class $\mathrm{T}(3.3 \% / 11.0)$ and in class SC (1.7\%/10.9).

Not included in the tables is our coding per lesson phase. Analysis of this coding revealed that in both classes the teachers were typically available to answer students' questions, both on guidelines and expectations and on content. Moreover, for both classes, we did not observe either of the two teachers to come across as unfair in the sense of treating students inconsequently (an element of disaffection or rejection).

Below, we continue with the results of the narrative analysis of manifestations of need supportive teaching. In this analysis, we mainly focused on differences between both classes, although similarities are briefly discussed as well to provide a more complete depiction of typical lessons. We found the positioning of these differences to show strong, but not perfect, overlap with the differences in terms of the levels of need supportive teaching described above.

\subsection{Narrative analysis of manifestations of need supportive teaching in class $\mathrm{T}$ and class SC}

For class instruction, the main differences between class T and class SC appeared to concern manifestations of autonomy support and thwart; both in lesson phases on task management and on content (see Sects. 4.2.1, 4.2.3).

For individual/small group instruction, the main differences between classes appeared to concern manifestations of autonomy support and thwart in both instruction on task management and content, as well as structure in instruction on content. Moreover, an important difference that related to manifestations of need supportive teaching appeared the time that was spent on instruction on process (see Sects. 4.2.2, 4.2.4).

Finally, similarities between both classes in manifestations of need supportive teaching existed as well. In phases of class instruction, manifestations of structure and chaos appeared rather similar in both classes, as did manifestations of involvement and disaffection. In phases of individual/small group instruction, it was manifestations of encouragement and informational feedback as components of structure, chaos, and involvement that appeared rather similar between classes (see Sect. 4.2.5).

\subsubsection{Class T, class instruction}

In class $\mathrm{T}$, the lessons consisted in instruction to the class as a whole varied with time for students to work on assignments individually or in small groups. In line with traditional views on instruction, the teachers directed the students' learning processes and made all decisions that concerned the design of the lessons as well as the tasks students worked on. This typically resulted in the teachers beginning their lesson 
with an overview of their lesson plan, as in the extract ${ }^{3}$ below. In the extract, the

T: Ok, listen. Idiom unit 5. For that you had to finish a few assignments.

Melissa: Oh

You had to do assignment 11 and 12 of Idiom unit 5. I want to propose the following. (...) Sven, can you stay with me in your attention? I want to check, discuss this with you. Next we continue with idiom box 6 for we want to finish those two little boxes idiom and - Melissa, yes we want that, we want that -

T: And next I also want to make a start with uh ..., grammar and spelling. You already did a large part of that. I want to get some overview. See if we checked every assignment, if you checked every assignment. Then the book is as good as finished. Then remains, the section writing then remains, and I want to do that in the coming weeks. So today idiom and a beginning of grammar. Is it clear for everybody what we are going to do?

T: Good. Now would you all put your homework in front of you?

teacher refrained from bringing up her plans for discussion. Although she did indicate she wanted "to propose" a plan, she asked for input only when she wanted to make sure that everybody had understood what they were supposed to do ("Is it clear for everybody what we are going to do?"). By not asking her students for other input, she did not seem open to adapt her lesson plan to incorporate students' choices or preferences; something that was affirmed by remarks as "Melissa, yes we want that". Because the students did not initiate discussions on the value of learning activities or call into question lesson plans, in teacher-student interactions on task management the teachers tended neither to support nor thwart students' autonomy. Indeed, the lack of discussion on task management appeared related to this class' traditional educational approach as the traditional view that teachers are expected to structure the course material and the way it is provided would have been somewhat at odds with asking students for an elaborate input on lesson plans.

Class instruction on content consisted in the teachers explaining new content while engaging in a dialogue with their students. The teachers actively encouraged the students to participate in these dialogues, either voluntarily or by turn-taking. Such teacher-class dialogues can yield good opportunities for teachers to provide cognitive autonomy support, in the sense of creating space for students to choose their own ways of approaching a problem and to define their own solution paths. At the same time, in such dialogues teachers can potentially thwart their students' cognitive autonomy by pressuring them and providing solution paths before they have had the time to reflect by themselves. Interestingly, we found the teacher-class dialogues in class $\mathrm{T}$ to vary a lot in this regard. First, a typical example is given of what we considered a teacher-class dialogue high in cognitive autonomy support.

In the extract below, the teacher encouraged the students to come up with different solutions by asking questions as: "Everybody agrees with Adam? -2?" or "Sure?".

\footnotetext{
3 All extracts have been translated from Dutch to English (original Dutch versions are available upon request). Names of students and teachers have been made anonymous.
} 
$\mathrm{T}:(\ldots)$ Adam, (...) 8 minus -10 is?

T: 0.2 ?

T: Everybody agrees with Adam? -2 ?

T: Who else, -2 ?

T: Steven?

T: Chloe?

$\mathrm{T}:-18$.

$\mathrm{T}:-12$. Oscar?

$\mathrm{T}$ : Everybody agrees with -2 ?

T: Sure?

T: Well, you have to keep thinking. I can take another sip of my coffee

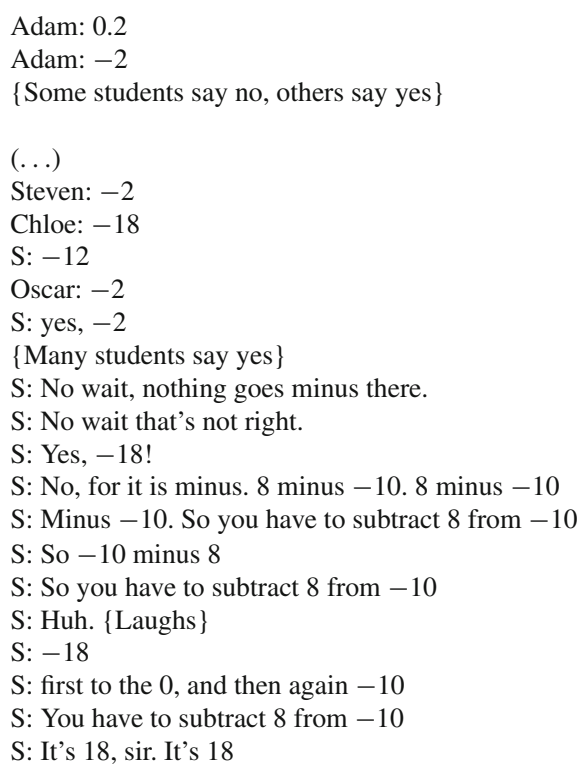

$\{\ldots\}$

Wrong answers were never ignored or corrected. The teacher did not actively encourage the students to elaborate on their strategies or different ways of thinking. He did, however, allow them time to reflect on their own and their classmates' solutions, thereby handing over part of the responsibility for their learning processes to the students. The students responded by elaborating on their thoughts, e.g. making remarks as "No wait, nothing goes minus here".

Interestingly, the students responded enthusiastically to their teacher's encouragements to engage in discussions. Despite their having little input in defining lesson plans or choosing the tasks they were working on, in these teacher-class dialogues they did seem to experience autonomy support indeed. From the SDT literature, it is known that students will only experience autonomy when they perceive the choices they are given as meaningful. An obvious prerequisite for cognitive autonomy support in teacher-class dialogues to be perceived as meaningful by students is that the topic of discussion fits within the students' current ability levels; in other words, the questions posed should not be too easy nor too difficult. In class T, as a result of its traditional educational approach, the students had been working on the same assignments simultaneously. Accordingly, it was relatively easy for the teachers to find topics of discussion that fitted all students.

As we mentioned above, in class $\mathrm{T}$ the teacher-class dialogues on content varied a lot. Below, a typical example is provided of such a dialogue that stands in contrast to the one presented above. Here, we considered the teacher to thwart the student's cognitive autonomy as he did not allow him time to reflect by himself. Instead, remarks as "this was told yesterday" indicated that the teacher had very clear ideas on how the student should approach the problem and pressured him to follow a pre-defined solution path. 
T: In which figure do the angles add up to $180^{\circ}$ ?

T: Anymore? This has been told yesterday too

T: Look at your book. It's in your book

T: Well...(...)

$\mathrm{T}$ : In a triangle, that is the right answer
\{No response $\}$

S: A half full

S: A full angle minus a straight angle

S: In a triangle

This interpretation was confirmed further by the teacher's lack of response when the student proposed a wrong answer ("A full angle minus a straight angle").

\subsubsection{Class T, individual/small group instruction}

When students were working on assignments individually or in small groups the teachers tended to check on all of them to affirm they knew how to continue with their work, e.g. with remarks as: "You can check your work." or "Is everything clear?". Such regular checking on students is in line with the traditional notion that teachers have a large responsibility for the various steps in their students' learning processes. Because the time students had available for working individually or in small groups was limited $(28.5 \%$ of 45 -min lessons, mostly divided over two phases, yielding a little over six minutes per phase), teacher-student interactions had to be short. Indeed, the teachers' nonverbal and verbal behaviour regularly were indicative for the feeling of being somewhat in a hurry. This was clear, for example, from their often slowly walking back even before an interaction had come to an end already, thereby expressing their willingness to move on.

As in class instruction, lesson plans or value of assignments was not discussed. Accordingly, next to the teachers checking on clarity of assignments, interactions on task management mostly were of disciplinary nature. At times, in these interactions the teachers thwarted their students' autonomy by being directive and inducing conditional regard. Below an extract of such an autonomy thwarting interaction is provided.

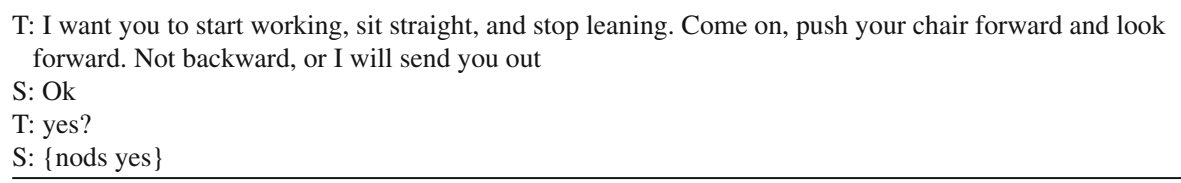

Teacher-student interactions on content typically consisted in the teachers providing brief answers to their students' questions. By always being available to answer questions when students needed help or support the teachers provided structure. However, the limited time they had available per interaction restrained their opportunities for discussion. Consequently, the teachers did not engage in providing structure by means of individual guidance, i.e. providing step-by-step directions thereby adjusting to the student(s). Further, the teachers typically did not support students' (cognitive) autonomy in these interactions, as they did not take time to encourage them to dis- 
cuss their own thoughts or solution paths. Below, a typical example is provided of an interaction on content.

T: If those add up to $90^{\circ}$. And that one \{points \} is 40 , how much is that

S: Ehm ... 100? one \{points $\}$ ?

T: That is together ... where is your pencil? \{grabs pencil\} Those are together $90^{\circ}$. That one \{points is 40 . How much is then that one \{points $\} ? 90^{\circ}-40^{\circ}$ is $50^{\circ}$

From the extract above, it can be seen how the teacher does not provide individual guidance, as he does not adjust to the student's prior understanding. Although he begins with asking her to tell him the answer she had in mind, when the answer she gives is not correct he does not follow-up on her response. Instead, he gives a very brief explanation only and does not check whether the student has understood. Further, he thwarts her cognitive autonomy by giving the correct answer before giving her any time for reflection, what is indicated, amongst others, by his not waiting for a reply the second time he posed the question "How much is that one?".

Finally, in contrast to class SC, we found that the teachers regularly (13.9 times per hour) expressed their disaffection, typically via remarks such as: "Will you please act normally".

\subsubsection{Class SC, class instruction}

Different from class $\mathrm{T}$, in class SC lessons either consisted in class instruction or in instruction to individual or small groups of students. Class instruction was used for explaining the period assignments students were handed and for providing brief introductions on relevant content. The teachers had designed global plans for these lessons, but students were encouraged to contribute additional ideas that could be incorporated.

When new period assignments were introduced, the teachers encouraged the students to express their thoughts on these assignments. In the extract below, a typical example is provided of an interaction on this topic.

Introducing a period assignment on poetry

T: Emma, when you received this little book, what did you think?

T: You thought: "Oh, ugh, what a subject”?

T: OK. And when in the end you started to work? Did you then have something like ... Did you change your opinion or do you still think "nah, that is not my cup of tea"?

T: Yes. The last?

$\mathrm{T}: \mathrm{OK}$
S: Yeah ... \{smiles $\}$

S: I didn't find it really very daft, but not like I find it really much fun

S: Yes

S: Yes 
In the extract below, it can be seen how a student is encouraged to express her thoughts. The teacher listened carefully and acknowledged her student's perspective by ending the interaction with "OK", spoken in very friendly tone. By accepting the students' opinions as valid, even when these were negative, the teacher supported her autonomy. The student appeared to respond by expressing her thoughts honestly. Interestingly, the teacher does not try to convince the student of the assignment's value. Later on in the lesson, however, when other students are asked to express their thoughts, they do provide arguments of why the assignment is of added value.

Whereas in class T substantial proportions of class instruction were contributed to teacher-initiated teacher-class dialogues on content, in class SC such dialogues were much rarer. Firstly, because in class SC much smaller proportions of class instruction were spent on content $(15.1 \%)$ than in class $\mathrm{T}(46.6 \%)$. Further, in line with social constructivist notions that students share responsibility for their own learning processes and that learning is a social process, students were encouraged to contribute topics for discussion. Below, a typical example is provided of such a student-initiated discussion.

T: But I think it is a very good one. Because ...

T: You have different ways. And I can show different things in different ways. And one time a table is very handy. And another time it's not. One time an arrows chain is handy and another time it's not. Sometimes I want to have it in a little graph, find that even easier. But it depends. And that's why I want for you to know them all. And you are right if it is just dividing by or times 4 , it is not so very write. But suppose I do times 3, plus 8 and then next divided by 2 ? Then it becomes a bit tough to do it out of my head. And then maybe a little table or an arrows chain is still easier. Do you get it? So you are right if you say, well, with this one I don't find that so very necessary. Well, that's right. But this is just to show how it works, right?

Intriguingly, discussions on content in class SC tended to have a very different nature than did the teacher-class discussions on content in class T. As can be seen from the extract above, it was mainly the student initiating the discussion and the teacher who were talking. The only other student joining the discussion expressed her disinterest, by uttering "Ooh. ..”. In conclusion, it seemed that neither were the students enthusiastic to participate, nor did the teacher encourage them do to so. Accordingly, for the teachers in class SC it was very untypical to provide their students with cognitive autonomy support in teacher-class dialogues. 
However, in the extract above the teacher did support the cognitive autonomy of the one student who initiated the discussion. Not only did the teacher listen carefully to the students' thoughts and ideas, remarks as "and you are right" also indicated his willingness to take the student's perspective. Further, the teacher fostered relevance of the method he has just explained by connecting the goal of using this method to effectively solve mathematical problems. By starting from the complaint uttered by the student "this is a very long way" and by concluding with asking the student whether he agreed, the teacher clearly aimed at convincing instead of coercing the student to agree, what is crucial to fostering relevance in an autonomy supportive manner.

\subsubsection{Class SC, individual/small group instruction}

In the lessons consisting in instruction to individual or small groups of students, the teachers intended to check on all of the students at least once a week. Further, they were available when students had questions. Because lesson time was longer and because they did not intend to check on their students as frequently, the teachers in class SC had more time available per interaction than did the teachers in class $\mathrm{T}$.

Different from class $\mathrm{T}$ and similar to class instruction, the teachers regularly supported their students' autonomy by fostering relevance both of the tasks at hand and content. In the extract below, an example is provided of such an autonomy supportive teacher-student interaction. In the extract, the teacher fostered relevance by providing

During arithmetic class

T: Arithmetic is a skill, like fitness. Do you play any sports?

T: Which one?

T: Hockey, you are in goal. Well, suppose you are not in goal. You need to be fit. Don't you?

T: Suppose, you don't do anything to maintain your fitness. Your fitness is good, but you don't do anything to maintain it.

T: Yes. The same. The same for arithmetic. You have to keep doing, keep doing. Your arithmetic fitness is very good, for you have finished everything. But you have to maintain it. And that is why you have to keep doing arithmetic

T: Yes? That is the idea behind arithmetic
S: Yes

S: Hockey, but I keep goal, haha S: Yes

S: You will become tardy.

S: Aaah

a meaningful rationale ("arithmetic is a skill") and linking this to the student's personal interest of hockey. By involving the student in his argument he seems to be able to convince her that practicing arithmetic is useful indeed, as indicated, for example, by her remark "You will become tardy". In interactions on content, the teachers regularly fostered their students' relevance as well; for example through the remarks such as "There are two ways. This is more the economist's way. I don't find that very handy for then you don't see so well what you have to do and when".

In interactions on content, the teachers typically provided structure by means of individual guidance, i.e. giving step-by-step directions thereby adjusting to the stu- 
dent(s). Further, by allowing students to follow their own solution paths they tended to support their students' cognitive autonomy.

In the extract below, an example of a teacher-student interaction on content is given.

T: Now suppose I take $20 \%$ of ... 320. Yes?

T: Yes. I just take something. Then I make a ratio table. Suppose Euro, like this \{draws table . What is $100 \%$ ?

T: How many percent do I want?

T: So where would I calculate to 1 ? 1 Euro or $1 \%$ ?

T: $1 \%$ \{writes down $\}$. How do you do that? How do I go from 100 to 1 ?

$\{\ldots\}$

T: $\{$ Writes down $\}$ And how do I go from 1 to 20 ?

T: Times 20, right? \{Writes down\} Must I do here too. Is 64 . Right, $20 \%$ of 320 is 64 . A ratio table always works.

T: Yes, you can do that too

\{Discussion of two more examples\}
S: Yes

S: $100 \%$ is just 320

S: 20

S: $\%$

S: Divided by 100

S: Times 20

S: Divided by 100 and then times 20 . Yes, I get it

In the extract above, the teacher continuously monitored the student's comprehension by asking her questions, e.g. "What is $100 \%$ ?". Further, by fashioning his step-by-step directions along the questions he posed, he could adjust to her prior understanding. Next to providing structure in this sense, the teacher supported the student's cognitive autonomy. By asking questions he actively encouraged her to engage in the interaction, thereby providing her with opportunities to express her thoughts and ideas. When she did, implicitly, propose an alternative solution path to approach the problem by saying: "Divided by 100 and then times 20. Yes, I get it", the teacher remarked "Yes, you can do that too", thereby supporting her to work in her own way.

A trigger for teachers to thwart students' autonomy has been argued to consist in the inherent power differences apparent in teacher-student relationships (Reeve 2009). In class SC, power differences appeared relatively small as was indicated, for example, by more informal remarks both by the teachers and the students, such as: "What are you occupying yourself with, except wearing a very cool t-shirt?" or interactions such as the extract below.

S: Marc, you are the best, now are we

Marc (T): No, sucking up doesn't work. Too finished? bad, isn't it?!

The fact that in class SC it was very rare for the teachers to thwart students' autonomy in interactions of a disciplinary nature, unlike in class $\mathrm{T}$, possibly resulted from relatively small power differences.

Next to teacher-student interactions on task management and content, in class SC interactions on students' learning processes were common as well. As in class T this type of interactions did not occur, in the extract below an example of such an interaction is provided. 
Interaction in reference to a student's headache during a test

T: How come it didn't go? You had a headache?

S: Yes, I had a headache

T: Could it also be caused by stress?

$\mathrm{S}$ : Yes, that is possible

T: When you think, one little thing goes wrong, and you S: I did know it, but then suddenly not anymore think: "Oh, I can't do any of it anymore". $\{\ldots\}$

In the extract above, the teacher was found to support the student's autonomy by providing her with space to express her feelings and thoughts on her own learning process. Initially, we interpreted the question "Could it also be caused by stress?" as the teacher imposing his own interpretation on the student. On second thought, we recognised that by voicing this interpretation that the teacher provided the student with the opportunity to discuss possible stress she experienced without having to be afraid to come across as complaining. Further, in this interaction we found the teacher to provide structure and involvement, by helping her directly as well as showing commitment to her learning process.

\subsubsection{Similarities in manifestations of need supportive teaching}

To provide a more complete depiction of what typical lessons, and more specifically, manifestations of need supportive teaching, looked like in both classes we continue by means of a brief discussion of manifestations of need supportive teaching that appeared typical in both classes.

In both classes, the teachers regularly provided their students with structure in the sense of encouragement and by giving informational feedback, for example, by brief remarks such as "Yeah, that one is difficult. David, can you help Nathan?" or "Bien, bien. Well checked.", or in longer comments during class instruction, as for example: "I am very glad someone made a little mistake, for what I find important is that if you write this down, this I have to do, and then, by accident, you make a typo or a small error in your calculations and you write down a wrong answer, then I don't mind so much". In both classes chaos appeared rare (see Table 2), but did occur at times, as the teachers gave evaluative feedback or discouraged their students, for example in remarks such as: "You don't make pretty sentences, Daniel".

Moreover, in both classes the teachers regularly expressed their involvement via brief remarks such as "Sorry to interrupt you, Tim" or "Did you already finish that completely? Super”.

\section{Discussion}

\subsection{Overview of findings}

In the present study, we aimed to gain in-depth understanding of what need supportive teaching entails in practice. For this purpose, we related manifestations of need supportive teaching to educational approaches of schools. Our narrative analysis of 
video-taped teacher-student interaction revealed striking differences as well as similarities between a prototypical traditional and a prototypical social constructivist class.

First, we found differences in manifestations of cognitive autonomy support. Cognitive autonomy support consists in providing students with problems that do not have clear-cut solutions, thereby giving them leeway in choosing their own approach and defining their own solution paths. In recent SDT literature, the importance of cognitive autonomy support has been stressed for triggering students' intrinsic desire to learn (e.g. Stefanou et al. 2004; Kunter and Baumert 2007; Tsai et al. 2008). In the traditional class, we found the teachers to occasionally initiate teacher-class dialogues that supported students' cognitive autonomy, to which the students responded by actively engaging in discussions on the problem posed. In the social constructivist class such teacher-class dialogues did not occur. The teachers in this class did, however, regularly support their students' cognitive autonomy during individual or small group instruction, something that was uncommon for the teachers in the traditional class.

This first difference between classes related to their respective educational approaches. In the social constructivist class opportunities to engage in autonomy supportive teacher-class dialogues seemed restricted by the differences in current knowledge levels between students that had resulted from the social constructivist notion that students share responsibility for their own learning process and the learning goals they choose. In addition, opportunities were hampered, as, in line with social constructivist views, during class instruction the teachers tended to encourage the students to initiate discussions on content instead of initiating these themselves. Typically, these student-initiated discussions did not trigger active participation by classmates. In the traditional class, on the other hand, teachers' opportunities to support students' cognitive autonomy in individual/small group instruction were restricted. Resulting from the traditional notion that teachers have a large responsibility for the various steps in students' learning processes, they had little time available per interaction. Accordingly, they lacked time to engage in the dialogues necessary for providing cognitive autonomy support.

Second, an important manifestation of autonomy supportive teaching when choice is constrained consists in acknowledging students' thoughts and feelings and fostering relevance. Teachers can foster relevance of a learning task by providing a rationale that is meaningful to the student(s). In the social constructivist class, the teachers regularly encouraged their students to express their opinions on the tasks at hand; both during class and during individual/small group instruction. When students expressed negative opinions, either the teacher or the class tended to respond by fostering relevance, thereby seemingly aiming to convince instead of coerce the student to agree (what is crucial to fostering relevance in an autonomy supportive manner). In the traditional class, discussions on the value of tasks did not occur; neither the teachers nor the students initiated such discussions. Indeed, this appeared in line with the traditional notion that teachers are expected to structure the course material as well as the way it is provided; something the students seemed to accept.

Third, an essential element of structure is providing individual guidance by giving step-by-step directions, thereby adjusting to the student's prior understanding. In the social constructivist class such individual guidance was very common, while in the traditional class it did not occur. Because giving individual guidance takes time, the first 
prerequisite is that teachers have time to do so. As mentioned above, for the teachers in the traditional class this prerequisite was not met which is the result of the traditional notion that teachers have a large responsibility in the various steps of students' learning processes and thus they had very limited time available per interaction.

Fourth, whereas in the traditional class we regularly found the teachers expressing their disaffection, in the social constructivist class this was very uncommon. Further, the interactions on students' learning processes that were common in the social constructivist class but not in the traditional class yielded specific manifestations of need supportive teaching; e.g. providing structure by guiding students in directing their learning processes. Finally, in the traditional class the teachers occasionally thwarted their students' autonomy in interactions of a disciplinary nature, while in the social constructivist class this did not occur. Following Reeve (2009), we argued this latter finding might have resulted from the relatively small power differences in the social constructivist class.

Fifth, following Reeve (2009), we argued that a traditional educational approach can strengthen teachers' feelings that they have to ensure their students' progress and, thereby, trigger an autonomy thwarting motivational style. Indeed, the results of our quantitative background analysis were indicative of relatively high levels of autonomy thwart in the traditional class; based on the narrative analysis we could, however, not draw conclusions on causal processes underlying this finding.

Finally, similarities between both classes consisted in the teachers regularly providing students with structure in the sense of encouragement and by giving informational feedback, whereas chaos appeared rare. Moreover, in both classes the teachers regularly expressed their involvement.

\subsection{Limitations and recommendations for future research}

A first limitation relates to the difficulties that are inherent in interpreting teacherstudent interactions in classrooms, namely, that not everything that is going-on in these complex contexts can be reckoned with. Because the main focus of this study was on communication that did take place and not on communication that did not take place, we might have missed manifestations of need thwart that resulted of a lack of attentiveness. In this regard, for example, the fact that the teachers in the social constructivist class did not check on their students as regularly as the teachers in the traditional class did, could have had negative implications that we did not anticipate. Despite this inherent limitation, for the aim of translating educational theory to practice and securing ecological validity, research conducted in the complex contexts of classrooms is crucial.

Second, because prior research on daily teaching practices in different types of schools is scarce, we had deliberately chosen a research design that limited interference by the researchers to an absolute minimum. This choice implied a limitation as it restrained the possibility of conducting interviews, for example. For future research, it would be of interest to complement observational research with data from interviews and video-stimulated recall to provide information on the students' (and teachers') own experiences and to deepen understanding of classrooms as contexts. 
Finally, for the future we recommend more studies that are focused on mapping what triggers teachers to adopt (elements of) need supporting or need thwarting motivational styles. Fortunately, in recent years SDT-researchers have begun shifting their attention to this topic and, amongst others, studies have been conducted on triggers in populations of students (Hornstra et al. 2013) and educational policies (Ryan and Niemiec 2009). More research remains necessary, however, to further the applicability of SDT into educational practice.

\subsection{Implications for educational theory and practice}

The present study was innovative as it focused on gaining in-depth understanding of what need supportive teaching entails in practice. The findings contribute to translating SDT to educational practice in two ways. First, the theoretical construct of need supportive teaching should be translated into practice. Having comprehension of the daily teaching practices that need supportive teaching and need thwarting teaching entail is of value for designing SDT-interventions. In addition, discussion on the basis of narratives can move forward the theoretical debate on what makes teaching need supportive (e.g. Stefanou et al. 2004; Assor et al. 2002).

Second, the findings of this study advance comprehension of how SDT interventions might adequately be implemented in practice. By showing how educational approaches trigger teachers' manifestations of need support and thwart and shape their opportunities in this regard, findings imply that long-lasting effects would be expected of teacher trainings only when these are tailored to fit educational approaches of schools (in line with Boekaerts and Minnaert 1999 or Rozendaal et al. 2005). Further, these findings suggest that in some situations first identifying what teachers' opportunities are will result in deciding on interventions that are school-wide or focused on educational policy instead of on individual teachers.

Acknowledgments We thank Hans Klompmaker, Anneke Kobs, and Sanne Feenstra for their help with collecting the video-material. This research was supported by grant 411-07-124 from the National Scientific Organisation of the Netherlands (NWO).

Open Access This article is distributed under the terms of the Creative Commons Attribution 4.0 International License (http://creativecommons.org/licenses/by/4.0/), which permits unrestricted use, distribution, and reproduction in any medium, provided you give appropriate credit to the original author(s) and the source, provide a link to the Creative Commons license, and indicate if changes were made.

\section{References}

Adams, P. (2006). Exploring social constructivism: Theories and practicalities. Education, 34(3), $243-257$.

Assor, A., Kaplan, H., \& Roth, G. (2002). Choice is good, but relevance is excellent: Autonomy-enhancing and suppressing teacher behaviours predicting students' engagement in schoolwork. British Journal of Educational Psychology, 72(2), 261-278.

Baumeister, R. F., \& Leary, M. R. (1995). The need to belong: Desire for interpersonal attachments as a fundamental human motivation. Psychological Bulletin, 117(3), 497-529.

Boekaerts, M. (2002). Bringing about change in the classroom: Strengths and weaknesses of the selfregulated learning approach. Learning and Instruction, 12, 589-604. 
Boekaerts, M., \& Minnaert, A. (1999). Self-regulation with respect to informal learning. International Journal of Educational Research, 31(6), 533-544.

Boekaerts, M., \& Niemivirta, M. (2000). Self-regulated learning: Finding a balance between learning goals and ego-protective goals. In M. Boekaerts, P. R. Pintrich, \& M. Zeidner (Eds.), Handbook of selfregulation (pp. 417-450). San Diego, CA: Academic Press.

Bolhuis, S., \& Voeten, M. J. (2001). Toward self-directed learning in secondary schools: What do teachers do? Teaching and Teacher Education, 17(7), 837-855.

Bowlby, J. (1979). The making and breaking of affectional bonds. London, UK: Tavistock.

Bozack, A. R., Vega, R., McCaslin, M., \& Good, T. L. (2008). Teacher support of student autonomy in comprehensive school reform classrooms. Teachers College Record, 110(11), 2389-2407.

Connell, J. P., \& Wellborn, J. G. (1991). Competence, autonomy, and relatedness: A motivational analysis of self-system processes. In Self-processes and development: The Minnesota symposia on child development (Vol. 23, pp. 43-77). Hillsdale, NJ: Lawrence Erlbaum Associates.

Deci, E. L. (1975). Intrinsic motivation. New York, NY: Plenum Press.

Deci, E. L., \& Ryan, R. M. (1985). Intrinsic motivation and self-determination in human behavior. New York, NY: Plenum Press.

Deci, E. L., Spiegel, N. H., Ryan, R. M., Koestner, R., \& Kauffman, M. (1982). Effects of performance standards on teaching styles: Behavior of controlling teachers. Journal of Educational Psychology, 74(6), 852-859.

Doyle, W. (1983). Academic Work. Review of Educational Research, 53(2), 159-199.

Doyle, W. (1986). Classroom organization and management. In M. C. Wittrock (Ed.), Handbook of research on teaching (3rd ed., pp. 392-431). New York, NY: Macmillan.

Dutch Inspectorate of Education. (2012). Onderwijsverslag. De Meren, the Netherlands: Inspectie van het onderwijs.

Flyvbjerg, B. (2006). Five misunderstandings about case-study research. Qualitative Inquiry, 12(2), 219245.

Gibbs, G. (1992). Assessing more students. Oxford: Oxford Brooks University.

Gottfried, A. E. (1985). Academic intrinsic motivation in elementary and junior high school students. Journal of Educational Psychology, 77(6), 631-645.

Greeno, J. G., Collins, A. M., \& Resnick, L. B. (1996). Cognition and learning. In R. C. Berliner \& D. C. Calfee (Eds.), Handbook of educational psychology (pp. 15-46). New York, NY: Macmillan.

Grolnick, W. S., Ryan, R. M., \& Deci, E. L. (1991). Inner resources for school achievement: Motivational mediators of children's perceptions of their parents. Journal of Educational Psychology, 83(4), 508517.

Harlow, H. F. (1958). The nature of love. American Psychologist, 13(12), 673-685.

Heath, C., Hindmarsh, J., \& Luff, P. (2010). Video in qualitative research. Analysing social interaction in everyday life. London, England: Sage.

Hickey, D. T. (1997). Motivation and contemporary socio-constructivist instructional perspectives. Educational Psychologist, 32(3), 175-193.

Hornstra, L., Mansfield, C., Van der Veen, I., Peetsma, T., \& Volman, M. (2013). Motivating teacher practices: The role of beliefs and context. Manuscript submitted for publication.

Klette, K., Lie, S., Anmarkrud, Ø., Arnesen, N., Bergem, O. K., Ødegaard, M., et al. (2005). Coding categories for video analysis of classroom activities with a focus on the teacher. Oslo, Norway: PISA+ study.

Kunter, M., \& Baumert, J. (2007). Who is the expert? Construct and criteria validity of student and teacher ratings of instruction. Learning Environments Research, 9(3), 231-251.

Malinowski, B. (1930). The problem of meaning in primitive languages. In I. A. Ogden \& C. K. Richards (Eds.), The meaning of meaning (pp. 296-336). London, England: Kegan Paul, Trench, Trubner, \& Co.

Marshall, H. H. (1988). Work or learning: Implications of classroom metaphors. Educational Researcher, 17(9), 9-16.

Maxwell, J. A. (2004). Causal explanation, qualitative research, and scientific inquiry in education. Educational Researcher, 33(2), 3-11.

Niemiec, C. P., \& Ryan, R. M. (2009). Autonomy, competence, and relatedness in the classroom: Applying self-determination theory to educational practice. Theory and Research in Education, 7(2), 133-144.

Oostdam, R., Peetsma, T., Derriks, M., \& Van Gelderen, A. (2006). Leren van het nieuwe leren: casestudies in het voortgezet onderwijs. Amsterdam, The Netherlands: SCO-Kohnstamm Instituut. 
Pelletier, L. G., Séguin-Lévesque, C., \& Legault, L. (2002). Pressure from above and pressure from below as determinants of teachers' motivation and teaching behaviors. Journal of Educational Psychology, 94(1), 186-196.

Perry, N. E., Turner, J. C., \& Meyer, D. K. (2006). Classrooms as contexts for motivating learning. In P. A. Alexander \& P. H. Winne (Eds.), Handbook of educational psychology (2nd ed., pp. 327-348). Mahwah, NJ: Lawrence Erlbaum Associates.

Prince, M. (2004). Does active learning work? A review of the research. Journal of Engineering Education, 3, 223-231.

Reeve, J. (2002). Self-determination theory applied to educational settings. In E. L. Deci \& R. M. Ryan (Eds.), Handbook of self-determination research (pp. 183-232). Rochester, NY: The University of Rochester Press.

Reeve, J. (2006). Teachers as facilitators: What autonomy-supportive teachers do and why their students benefit. The Elementary School Journal, 106(3), 225-236.

Reeve, J. (2009). Why teachers adopt a controlling motivating style toward students and how they can become more autonomy supportive. Educational Psychologist, 44(3), 159-175.

Rozendaal, J. S., Minnaert, A., \& Boekaerts, M. (2005). The influence of teacher perceived administration of self-regulated learning on students' motivation and information-processing. Learning and Instruction, 15(2), 141-160.

Ryan, R. M. (1995). Psychological needs and the facilitation of integrative processes. Journal of Personality, 63(3), 397-427.

Ryan, R. M., \& Connell, J. P. (1989). Perceived locus of causality and internalization: Examining reasons for acting in two domains. Journal of Personality and Social Psychology, 57(5), 749-761.

Ryan, R. M., \& Deci, E. L. (2000). Self-determination theory and the facilitation of intrinsic motivation, social development, and well-being. American Psychologist, 55(1), 68-78.

Ryan, R. M., \& Deci, E. L. (2002). An overview of self-determination theory: An organismic-dialectical perspective. In E. L. Deci \& R. M. Ryan (Eds.), Handbook of self-determination research (pp. 3-33). Rochester, NY: The University of Rochester Press.

Ryan, R. M., \& Niemiec, C. P. (2009). Self-determination theory in schools of education: Can an empirically supported framework also be critical and liberating? Theory and Research in Education, 7(2), 263-272.

Shepard, L. (2000). The role of assessment in a learning culture. Educational Researcher, 29(7), 4-14.

Shuell, T. (1996). Teaching and learning in a classroom context. In D. C. Berliner \& R. C. Calfee (Eds.), Handbook of educational psychology (pp. 726-764). New York, NY: Prentice Hall International.

Slavin, R. E. (2012). Educational psychology. Theory and practice (10th ed.). New Jersey, NJ: Pearson.

Stefanou, C. R., Perencevich, K. C., DiCintio, M., \& Turner, J. C. (2004). Supporting autonomy in the classroom: Ways teachers encourage student decision making and ownership. Educational Psychologist, $39(2), 97-110$.

Stroet, K. (2014). Studying motivation in classrooms. Effects of teaching practices on early adolescents' motivation. Doctoral dissertation. Retrieved from http:/www.faculties/gmw/2014/k.f.a.stroet/.

Stroet, K., Opdenakker, M.-C., \& Minnaert, A. (2013). Effects of need supportive teaching on early adolescents' motivation and engagement: A review of the literature. Educational Research Review, 9, 65-87.

Toulmin, S. (1972). Human understanding. Princeton, NJ: Princeton University Press.

Tsai, Y.-M., Kunter, M., Lüdtke, O., Trautwein, U., \& Ryan, R. M. (2008). What makes lessons interesting? The role of situational and individual factors in three school subjects. Journal of Educational Psychology, 100(2), 460-472.

Vermunt, J. D., \& Verloop, N. (1999). Congruence and friction between learning and teaching. Learning and Instruction, 9(3), 257-280.

Vygotsky, L. S. (1962). Thought and language. Cambridge, MA: Harvard University Press.

Vygotsky, L. S. (1978). Mind in society: The development of higher psychological processes. Cambridge, MA: Harvard University Press.

Kim Stroet recently finished her Ph.D. research at the Department of Educational Sciences, Centre for Special Needs Education and Youth Care, University of Groningen. She is appointed as assistant professor at the Department of Education and Child Studies at Leiden University. Her research interests are teacherstudent interactions, motivation, and self-regulation. 
Marie-Christine Opdenakker is associate professor and Rosalind-Franklin fellow at the Groningen Institute for Educational Sciences (GION), University of Groningen. Her research interests are educational and teacher effectiveness, teacher-student interactions, and motivation.

Alexander Minnaert is full professor in Special Needs and Clinical Education at the Department of Educational Sciences, Centre for Special Needs Education and Youth Care, University of Groningen. His research interests are motivation, emotion, self-regulation, and learning (disabilities). 